\title{
ОЦЕНКА ВЛИЯНИЯ СФЕРЫ ОБРАЗОВАНИЯ НА ЭКОНОМИЧЕСКОЕ РАЗВИТИЕ СТРАНЫ
}

\author{
Ахмедова Эсмира М., \\ диссертант Азербайджанского Экономического Государственного Университета (UNEC), \\ преподаватель, Азербайджанская Республика, г. Баку
}

DOI: https://doi.org/10.31435/rsglobal_ijite/30042019/6455

\section{ARTICLE INFO}

Received 12 February 2019

Accepted 15 April 2019

Published 30 April 2019

\section{KEYWORDS}

higher education, socio-economic development, human development index, human capital, expenditures, state budget. \begin{abstract}
This article indicates the results a comparative analysis the financing of the advanced countries of the world and similar indicators of Azerbaijan during the period active development of education and modernization of the economy. The methodology work is the fundamental works of foreign scientists, such as reports of the Organization for Economic Cooperation and Development (OECD), human development index indicators in the field of determining and assessing the dependence of socio-economic development on public investment in education. It is displayed that Azerbaijan has resources and potential for growth of human capital, for social and economic development of the country. On the basis of the research, some conclusions and proposals are presented that contribute to improving the prospects for the economic development of Azerbaijan.
\end{abstract}

\footnotetext{
Citation: Ахмедова Э. М. (2019) Ocenka Vliyaniya Sfery Obrazovaniya na Ekonomicheskoe Razvitie Strany. International Journal of Innovative Technologies in Economy. 3(23). doi: 10.31435/rsglobal_ijite/30042019/6455
}

Copyright: (C) 2019 Ахмедова Э. М. This is an open-access article distributed under the terms of the Creative Commons Attribution License (CC BY). The use, distribution or reproduction in other forums is permitted, provided the original author(s) or licensor are credited and that the original publication in this journal is cited, in accordance with accepted academic practice. No use, distribution or reproduction is permitted which does not comply with these terms.

Введение. Значимость вклада сферы образования в развитии общества подтверждается мировым опытом. Он показывает, что все страны, успешно преодолевшие переход к современным рыночным отношениям (например, послевоенные Германия и Япония, США 60х годов), рассматривали сферу высшего образования как приоритетную и исходили из этого в своей инвестиционной политике, в которой расходы на сферу образования считались одними из основополагающих показателей социально - экономического развития страны. С одной стороны, это во многом объясняется и тем, что данный показатель отражает степень внимания, которое уделяет общество и государство образованию граждан. С другой стороны, образование имеет собственную значимость, так как оно способствует расширению кругозора людей, повышает возможность самореализации человека как личности, способствует материальному благополучию и здоровому образу жизни большей части населения страны. Таким образом, инвестиции в сферу образования являются не только важным способом качественного увеличения человеческого капитала страны, а также улучшения перспектив социально - экономического развития.

Проблеме влияния сферы образования на экономическое развитие стран посвящего большое количество работ ученых разных стран. Не смотря на это, вопрос о точной величине этого влияния остается открытым. Так, анализ влияния качества школьного образования на межстрановые различия в темпах экономического развития, выполненный в работе Hanushek, Kimko (2000), показывает, что качество может быть очень значимым фактором. Hanushek, Kimko (2000) после проведения ряда тестов на причинность пришли к выводу о прямом влиянии качества образования на экономический рост [1, стр. 67].

В работах Michael (1982) и Wolfe, Zuvekas (1995) показано, что более образованные избиратели более ответственно относятся к выборам в различные органы власти. Lochner, 
Moretti (2001) в своей работе говорят о положительном влиянии образования на снижение уровня преступности. Среди работ, посвященных экономическому росту, в которых делался подобный вывод, можно выделить работы Lucas (1988), Barro (1991), Barro, Sala-I-Martin (1995). Среди международных сопоставлений эффективности расходов на общественный сектор можно выделить работы Fakin, Crombrugghe (1997),

Afonso, Schuknecht, Tanzi (2003) в своей работе провели сравнительный анализ для стран ОЭСР. Clements (2002) оценил эффективность образовательных расходов для стран Европы, а в работе Gupta, Verhoeven (2001) проведено исследование образования и здравоохранения для стран Африки.

Согласно данным Организации экономического сотрудничества и развития (OECD, 2001), для более образованных работников не только заработные платы выше, но и существуют бо́льшие возможности в трудоустройстве и меньше риск остаться без работы.

А. Мэддисон, автор исследования «Динамические силы капиталистического развития», вывел зависимость, согласно которой увеличение ассигнований на образование на $1 \%$ ведет к увеличению валового внутреннего продукта страны на 0,35\%.

Как правило, экономисты рассматривают расходы на школьное образование как инвестиции и в обучающихся, и в общество в целом. Опыт последних лет показывает, что расходы на образование - эффективные, а главное - необходимые инвестиции, так как в последнее время в мире неуклонно растет спрос на квалифицированную рабочую силу [1, стр. 7]. Уровень национальных расходов на образование - это величина, которая отражает общий объем государственных и частных расходов на образование в течение года. Она охватывает государственные бюджеты всех уровней, частные фонды, внешние заимствования, гранты и пожертвования от международных учреждений и организаций, неправительственных организаций.

Ниже представлена гистограмма, составленная согласно рейтингу стран мира по уровню расходов на образование в \% к ВВП.

Гистограмма. Уровень расходов на образование в \% к ВВП. Источник The World Bank: World Development Indicators 2014.

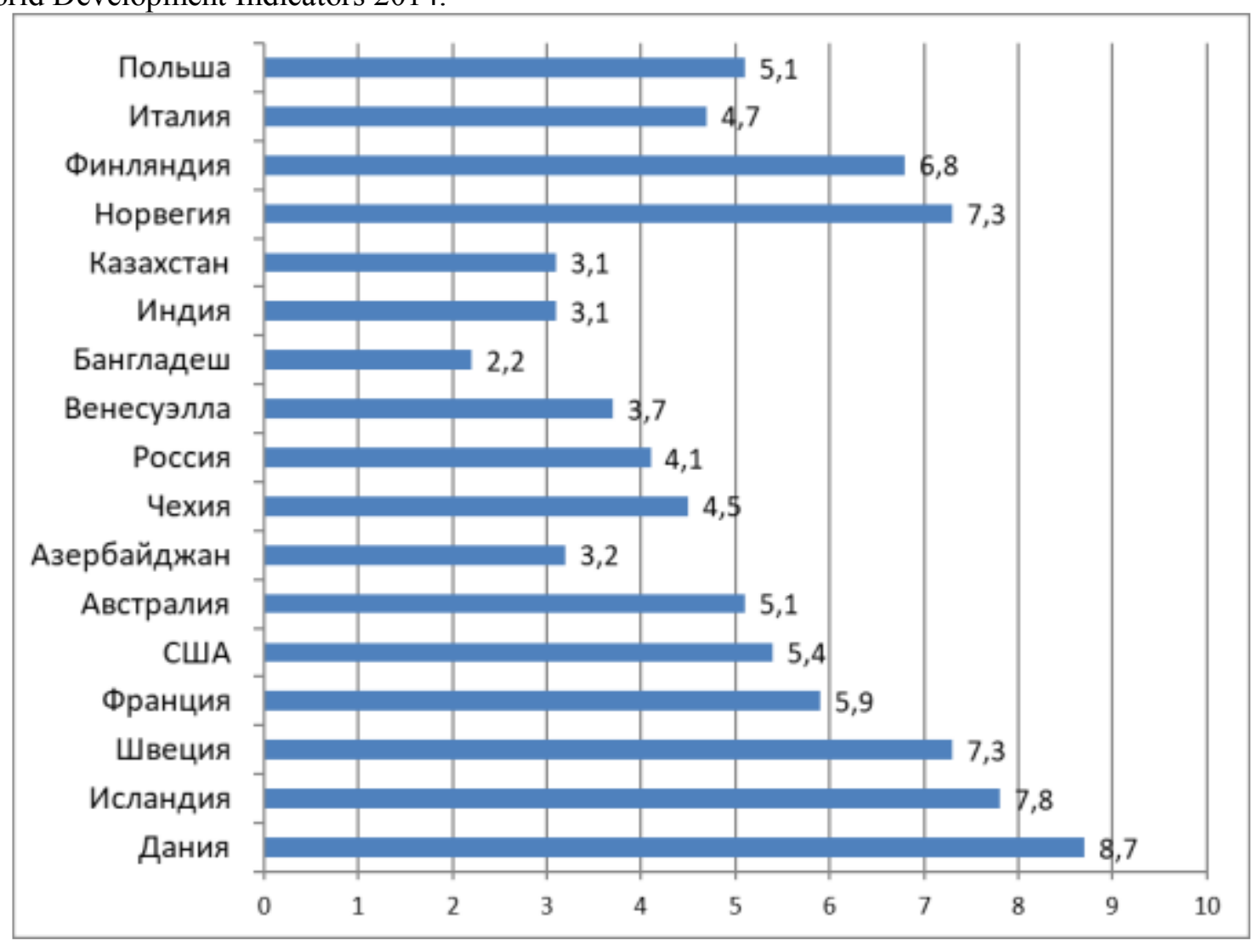

Puc. 1.

Источник: Организаччии экономического сотрудничества и развития (OECD) 
Совокупным показателем, отражающим уровень развития человека в стране является индекс человеческого развития (ИЧР). Иногда этот индекс используют в качестве синонима таких понятий как «качество жизни» или «уровень жизни». Индекс измеряет такие важные и ключевые показатели, как состояния здоровья, получения образования и фактического дохода её граждан, по трём основным направлениям:

$\checkmark$ доступность образования - данный показатель измеряется на основе уровня грамотности взрослого населения и совокупным валовым коэффициентом охвата образованием;

$\checkmark$ здоровье и долголетие - данный показатель измеряется на основе показателя ожидаемой продолжительности жизни при рождении;

$\checkmark$ достойный уровень жизни - данный показатель измеряется величиной валового внутреннего продукта на душу населения (по паритету покупательной способности, выраженному в долларах США).

Эти три направления измерений группируются в виде числовых значений от 0 до 1 , среднее геометрическое которых представляет собой совокупный показатель ИЧР в диапазоне от 0 до 1. Затем государства ранжируются на основе этого показателя. В результате, все страны в рейтинге классифицируются четырьмя категориями:

1. страны с очень высоким уровнем ИЧР;

2. страны с высоким уровнем ИЧР;

3. страны со средним уровнем ИЧР;

4. страны с низким уровнем ИЧР.

Таблица 1. Общие расходы на третичное образование в странах «Большой восьмерки»

\begin{tabular}{|c|c|c|c|c|c|}
\hline \multirow[b]{2}{*}{ Страна } & \multirow{2}{*}{$\begin{array}{c}\text { ВВП } \\
\text { на душу } \\
\text { населения, } \\
\text { тыс. дол. * }\end{array}$} & \multirow{2}{*}{$\begin{array}{c}\text { Расходы на } \\
\text { третичное } \\
\text { образование } \\
\text { в \% к ВВП** }\end{array}$} & \multicolumn{3}{|c|}{$\begin{array}{c}\text { Расходы на одного учащегося в } 5 \text { к ВВП на душу } \\
\text { населения (в национальных валютах) }\end{array}$} \\
\hline & & & $\begin{array}{c}\text { Всего по } \\
\text { третичному } \\
\text { образованию }\end{array}$ & $\begin{array}{c}\text { Уровень среднее } \\
\text { профессионального } \\
\text { образования }\end{array}$ & $\begin{array}{c}\text { Уровень } \\
\text { высшего } \\
\text { образования }\end{array}$ \\
\hline США & 33725 & 2,3 & 57 & н.д. *** & Н.Д. \\
\hline Канада & 26443 & 2,5 & 57 & Н.Д. & н.Д. \\
\hline Япония & 24968 & 1,0 & 41 & 31 & 43 \\
\hline Германия & 24601 & 1,1 & 42 & 22 & 46 \\
\hline Франция & 23068 & 1,1 & 34 & 37 & 33 \\
\hline Италия & 23937 & 0,8 & 32 & 30 & 32 \\
\hline $\begin{array}{c}\text { Великобри } \\
\text { тания } \\
\end{array}$ & 23312 & 1,1 & 41 & н.Д. & н.Д. \\
\hline Россия & 6067 & 1,1 & 27 & 13 & 35 \\
\hline
\end{tabular}

* по паритету покупательной способности

** в национальных валютах

***н.д. - нет данных

Менее богатые страны обычно поддерживают расходы в сфере третичного образования на одного студента уровня средне профессионального образования около 50\% от подушегово ВВП, а на одного студента уровня высшего образования - в пределах 100-150\% от подушевого ВВП. Это позволяет хотя бы частично компенсировать разрыв в уровне финансирования с наиболее богатыми странами и уменьшить различия в его качестве.

Согласно международной методике и учитывая количество студентов и подушевой ВВП на 2014 год, финансирование третичного образования в Азербайджане должно составлять более $26 \%$ бюджета, выделяемого для сферы образования. Это составляет 409-433 млн манат или 524-555 млн долларов в США на состояние 2014 года. В странах, входивших в 2003 г. в двадцатку лидеров по ИРЧП, доля государственных расходов на третичное образование в общем образовательном бюджете правительства составляла в среднем 24\%, находясь в диапазоне от 15\% в Японии до $36 \%$ в Канаде. 
Таблица 2. Расходы на образование на 1 учащегося в процентах к ВВП на душу населения

\begin{tabular}{|c|c|c|c|c|c|}
\hline $\begin{array}{c}\text { Группа } \\
\text { стран }\end{array}$ & $\begin{array}{c}\text { Начальное } \\
\text { образование }\end{array}$ & $\begin{array}{c}\text { Среднее } \\
\text { образование }\end{array}$ & $\begin{array}{c}\text { Послесреднее } \\
\text { не высшее }\end{array}$ & $\begin{array}{c}\text { Высшее } \\
\text { образование } \\
\text { типа В }\end{array}$ & $\begin{array}{c}\text { Высшее } \\
\text { образование } \\
\text { типа A }\end{array}$ \\
\hline I & 19,4 & 26,0 & 30,0 & 30,5 & 45,4 \\
\hline II & 17,6 & 23,3 & 21,8 & 28,3 & 45,0 \\
\hline III & 15,2 & 18,6 & н.Д. & 49,0 & 91,8 \\
\hline IV & 14,4 & 21,2 & н.Д. & 50,9 & 163,3 \\
\hline
\end{tabular}

По Индексу человеческого развития (ИЧР) 2015 года Азербайджан находился на 78 месте с ИЧР 0,751 и входил во вторую группу стран - стран с высоким уровнем ИЧР.

Учитывая колличество школьников на 2014-2015 учебный год (1 322 тыс. человек), и затраты на одного учащегося к ВВП на душу населения в соотвествии с рекомендациями ЮНЕСКО и мировым опытом, нетрудно подсчитать, что они составили почти $64 \%$ бюджета сферы образования в 2014 году. Если принять во внимание только расходы на третичное и школьное образование в Азербайджане согласно мировому опыту для менее богатых стран чтобы частично компенсировать отставание от финансирования образования в развитых странах и не терять при этом качество услуг сферы образования, необходимо учеть, что в 2014 году эти расходы составили $89 \%$ средств, выделяемых на сферу образования, что составляет 1 460,8 млн манат при минимальном финансировании и 1485,2 млн манат при максимальном расчете финансированичя средств.

Согласно данным Государственного Коммитета по Статистике Азербайджана, с января по ноябрь, т. е. за 11 месяцев 2015 года (примечание: 2015 г. - до девальвационный период в экономике Азербайджана) на финансирование нужд сферы образования было выделено 1268,2 млн манат. Очевидно, эти расходы не достаточно покрывают финансирование образования послевузовского уровня, содержания штата преподавателей и прочих расходов. С учетом этих показателей и расходов госбюджета Азербайджана на 2015 год с трудом можно считать финансирование сферы образования на полноценном уровне.

Ведущие страны мира в период развития третичного образования (С 1990 по 2000-е годы) тратили на его развитие от 4 до 9\% ВВП. После достижения развития в этой отрасли и получения отдачи, доля расходов в ВВП на образование была снижена до 2-4\% в год. Необходимо отметить, что при этом общее финансирование сферы образование не уменьшилось. Произошло замещение государственных средств собственными средствами предприятий и организаций.

Рассмотрим показатели государственных расходов развитых стран мира в период форсированного развития сферы образования и модернизации экономики этих стран, приведенную в таблице 2.

Таблица 3. Показатели государственных расходов на образование

\begin{tabular}{|l|c|c|c|c|}
\hline \multirow{2}{*}{ Показатели } & \multicolumn{3}{|c|}{ Государственные расходы на образование } \\
\cline { 1 - 5 } & \multicolumn{3}{|c|}{ в от ВВП } & \multicolumn{2}{c|}{$\begin{array}{c}\text { \% от общего уровня } \\
\text { государственных расходов }\end{array}$} \\
\hline Страны & 1990 & $2000-2002$ & 1990 & $2000-2002$ \\
\hline Норвегия & 7,0 & 7,6 & 14,6 & 16,2 \\
\hline Исландия & 5,4 & 6,0 & н.Д. & н.Д. \\
\hline Австралия & 4,9 & 4,9 & 14,8 & 13,3 \\
\hline Люксембург & 3,1 & 4,1 & 10,4 & 8,5 \\
\hline Канада & 6,5 & 5,2 & 14,2 & 12,7 \\
\hline Швеция & 7,0 & 7,7 & 13,8 & 12,8 \\
\hline Швейцария & 4,9 & 5,8 & 18,7 & 15,1 \\
\hline Ирландия & 4,8 & 5,5 & 10,2 & 13,5 \\
\hline Бельгия & 5,0 & 6,3 & н.д. & 11,6 \\
\hline США & 5,1 & 5,7 & 12,3 & 17,1 \\
\hline Япония & н.Д. & 3,6 & н.Д. & 10,5 \\
\hline Нидерланды & 5,7 & 5,0 & 14,8 & 10,7 \\
\hline Финляндия & 5,5 & 6,4 & 11,9 & 12,2 \\
\hline Дания & н.Д. & 8,5 & н.Д. & 15,3 \\
\hline Великобритания & 4,8 & 5,3 & н.Д. & 11,5 \\
\hline
\end{tabular}


Источник: Организации экономического сотрудничества и развития (OECD)

Азербайджан в последние годы также находится в состоянии модернизации экономики и системы образования, при более скромных расходах на эту сферу. Тем не менне тенденция увеличения расходов в удельном весе от государственного бюджета в Азербайджане положительная. В последние годы государство стало уделять большее внимание сфере образования, повысив расходы бюджета. Так, за 5 лет с 2013 по 2018 года расходы на образование выросли почти на 1,7 процентных пункта. По удельному весу уровня государственных расходов Азербйджан почти на таком же уровне как и Люксембург в свое время (см. Таблицу 3,4).

Таблица 4. Государственные расходы на образование в Азербайджане

\begin{tabular}{|c|c|c|c|c|c|c|c|}
\hline \multicolumn{4}{|c|}{ Г \% к ВВП } & \multicolumn{5}{|c|}{ в \% в Госбюджете } \\
\hline $\mathbf{2 0 1 0}$ & $\mathbf{2 0 1 3}$ & $\mathbf{2 0 1 5}$ & $\mathbf{2 0 1 8}$ & $\mathbf{2 0 1 0}$ & $\mathbf{2 0 1 3}$ & $\mathbf{2 0 1 5}$ & $\mathbf{2 0 1 8}$ \\
\hline 2,78 & 2,5 & $2,3^{*}$ & 2,06 & 11,3 & 7,7 & 8 & 8,4 \\
\hline
\end{tabular}

*данные за январь - ноябрь 2015 г

источник: Государственный Коммитет Азербайджанской Республики

На становление каждого нового профессора в США независимо от предмета его исследований требуется в среднем 1,2 млн долл США. Профессор, который остается в университете более 25 лет после получения права бессрочного пребывания в должности приносит около 13 млн долл США в результате своей научно - исследовательской деятельности. Нельзя считать совпадением то, что самые современные исследования проводятся в лабораториях, сотрудники которых получают достойную плату.

По данным американских ученых, исследующих проблемы экономики образования, на долю последнего приходится $15-20 \%$ роста национального дохода. Кроме того, от $20 \%$ до 40\% дает совершенствование научных знаний и их применение - процесс, в котором ведущая роль принадлежит высшим учебным заведениям.

В результате форсированного развития, образование в развитых странах сегодня превратилось в одну из самых динамично развивающихся сфер экономики и общества. Так, по подсчетам специалистов США, Голландии, Японии, образование - это самая прибыльная отрасль: она дает существенную прибыль (4-5 валютных единиц на 1 единицу затрат на обучение). А в национальном бюджете Австралии доходы от образования стоят на третьем месте после таких высокорентабельных отраслей, как добыча угля и туризм.

Проводимая в Азербайджанской Республике политика инновационной модернизации и диверсификации экономики предъявляет повышенные требования к эффективности организации системы образования, являющейся в настоящее время одним из стратегических факторов социально - экономического развития. В связи с этим предпринимаются систематические меры для реализации поставленных задач. Так, 19 июня 2009 года был принят Закон Азербайджанской Республики об Образовании. 24 октября 2013 г. принята государственная стратегия по развитию образования в Азербайджанской Республике. В утвержденной в 2012 г. Концепции развития «Азербайджан 2020: взгляд в будущее», а также в стратегических дорожных картах по национальной экономике и основным секторам экономики четко отмечено увеличивающуюся роль сферы образования в современном мире.

\section{Основные выводы и рекомендации.}

В данной статье был проведен сравнительный анализ структуры финансирования сферы образования сопоставимых периодов развития: период форсированного развития сферы образования и диверсификаций экономик развитых стран и аналогичных показателей Азербайджанской Республики. Рассмотрены и показаны значение и роль сферы образования на современном этапе развития. В результате проведенного исследования сделаны следующие выводы и предложены нижеследующие рекомендации:

1. Целесообразно расширять систему высшего и послевузовского образования в стране. Поскольку, сфера образования на уровне средне профессионального образования и высшего образования уровня носит стратегический характер и является ключевым фактором роста экономического роста экономики страны на совремнном этапе. 
2. Увеличивать как количественные, так и качественные показатели системы образования страны. Необходимо рассмотреть вопросы поддержки широкомасштабного образования, подготовки и переподготовки, профессионального образования взрослого населения.

3. Провести критический анализ системы образования Азербайджана на всех уровнях с целью сопоставления в контексте международных показателей и ликвидации отрицательных факторов влияния.

4. Увеличивать финансирование системы образование. Главным фактором здесь является то, чтоб финансирование носило целевой характер. Например, учредить Эндаумент целевой фонд, предназначенный для использования некоммерческих целей - образования, медицины, культуры.

5. Содействовать научному международному сотрудничеству в стратегических сферах и наукоемких отраслях.

6. Создание научно-исследовательских центров (к примеру, на базе существующих вузов) для превращения их точки развития и экономического роста страны.

7. Расширение политики выявления и сосредоточение талантов среди студентов.

8. Учитывая то, что объем научно - технической информации удваивается каждые 7 10 лет, специалисты всех уровней обязаны осваивать новые технологии, развивать навыки самообразования и быть вовлечены в систему непрерывного образования и повышения квалификации.

Сделав ставку на сферу образования, можно будет обеспечить стране конкурентоспособность экономики за счет подготовки квалифицированной рабочей силы, отличающейся высокой производительностью и гибкостью, а также за счет создания, внедрения и распространения новых идей и технологий. Ведь усиливавшееся соревнование государств в сфере высшего образования - это по сути, соревнование экономическое, поскольку образование в современных усовиях стало основным источником социальноэкономического роста стран.

\section{ЛИТЕРАТУРА}

1. Кнобель, Александр Юрьевич Влияние государственных расходов на качество образования в России /А. Кнобель, И. Соколов, Е. Худько; под ред. С. Г. Синельникова-Мурылева. М.:Издательство Ин-та Гайдара, 2011. - 164 с.: ил. - (Научные труды / Ин-т эконом. политики им. Е.Т. Гайдара; № 152P). - ISBN 978-5-93255-335-0.

2. Прокопьева Анастасия Вячеславовна, Рыбаков Лев Николаевич, Пчёлкина Валентина Викторовна Влияние образования на формирование качественного уровня человеческого капитала в региональной экономике // Вестник ЧГУ. 2012. №1. URL: https://cyberleninka.ru/article/n/vliyanieobrazovaniya-na-formirovanie-kachestvennogo-urovnya-chelovecheskogo-kapitala-v-regionalnoyekonomike (дата обращения: 24.04.2019).

3. Acemoglu, D., Angrist J. (2000). How large are the social returns to education? Evidence from compulsory schooling laws // In: B.S. Bernanke and K. Rogoff, eds., NBER Macroeconomics Annual 2000 (MIT Press, Cambridge, MA). P. 9-59.

4. Barro R.J. (1991). Economic growth in a cross section of countries //Quarterly Journal of Economics. Vol. 106. P. 407-443.

5. Bascia N. (2010). Reducing Class Size: What Do We Know?, Ontario Institute for Studies in Education.

6. Betts J.R. (1996). Is there a link between school inputs and earnings?Fresh scrutiny of an old literature // in G. Burtless (ed.) Does Money Matter? The Effect of School Resources on Student Achievement and Adult Success. Brookings, Washington, DC. P. 141-191.

7. The Education, Audiovisual and Culture Executive Agency (EACEA).Private education in the European Union. Organisation, administration and the public authorities' role. Netherlands: http://eacea.ec.europa.eu/eurydice/ressources/eurydice/pdf/011DN/011_NL_EN.pdf.

8. Education at a Glance 2003, 2009, 2016 // Organisation for Economic Co-operation and Development, www.oecd.org/.

9. Fakin B., de Crombrugghe A. (1997). Fiscal Adjustment in Transition Economies: Social Transfers and the Efficiency of Public Spending, a Comparison with OECD Countries // Policy Research Working Paper N 1803. The World Bank, Washington.

10. Доклад ВБ, «Знания на службе развития: 1998-1999 гг.

11. Создание университетов мирового класса, ВБ, Джамиль Салми, М., 2009

12. Вульфсон Б.Л. Стратегия развития образования на Западе на пороге XXI века.- М., 1999.- С.34. 
13. The Three Strands of Innovation: an interview with Jean-Francais Rischard by Audrey Liounis // Development Outreach: Putting Knowledge to Work for Development / The World Bank Institute. Washington, 2010. P. 10-12.

14. Azərbaycan Respublikasının Dövlət Statistika Komitəsi “Sosial, İqtisadi İnkişaf”, yanvar - dekabr, 1991, 2000, 2015

15. Дерек Бок «Университеты в условиях рынка. Коммерциализация высшего образования», ВШЭ, М., 2012

16. Бертон Р.Кларк «Поддержание изменений в университетах», ВШЭ,М., 2011

17. Майбуров И. Высшее образование в развитых странах // Высшее образование в России. 2003. №2. URL: https://cyberleninka.ru/article/n/vysshee-obrazovanie-v-razvityh-stranah (дата обращения: 25.04.2019).

18. Global Innovation Index, 2016, URL: https://www.globalinnovationindex.org/UploadedFiles/Events/EventHeader a0e061763d4646638f6da081ed486ec7.PDF

19. Электронный ресурс: http://stat.edu.ru/doc/Rus_education.pdf

20. Электронный ресурс: http://www.gramota.net/materials/3/2012/7-3/8.html

21. Электронный ресурс: http://economicarggu.ru/2012_3/tebiev.pdf

22. Электронный pecypc: http://www.monographies.ru/ru/book/section?id=7185

23. Электронный ресурс: http://oecdru.org/zip/9213028e5.pdf

24. Электронный ресурс:http://demoscope.ru/weekly/2009/0375/analit02.php

25. Электронный ресурс:http://hdr.undp.org/en/reports/global/hdr2007-\%202008/chapters/russian

26. Электронный pecypc:http://www.gramota.net/materials/3/2012/7-3/8.html

27. Электронный ресурс:http://hdr.undp.org/sites/default/files/2015_human_development_report.pdf

28. Электронный ресурс: Human Development Report 2015, Work for Human Development

29. Электронный pecypc:http://demoscope.ru/weekly/2015/0629/barom04.php

30. Электронный pecypc:http://gtmarket.ru/news/2015/12/16/7285

31. Электронный pecypc:http://gtmarket.ru/ratings/expenditure-on-education/info 